\title{
Pengembangan Strategi Pelestarian Budaya di Sanggar Tari Bali Saraswati Yogyakarta
}

\author{
Putu Merina Rahayu \\ Program Pascasarjana Institut Seni Indonesia Yogyakarta \\ merinarahayu_putu@yahoo.co.id
}

\begin{abstract}
Abstrak
3HQHONOQmengenai Pengembangan Strategi Pelestarian Budaya di Sanggar Tari Bali Saraswati Yogyakarta bertujuan untuk mengidentifikasi strategi yang digunakan selama ini pada Sanggar Tari Bali Saraswati. Selain itu juga untuk menganalisis faktor internal dan eksternal serta memformulasikan pengembangan strategi yang dilakukan Sanggar Tari Bali Saraswati di Yogyakarta. Metode penelitian mengenai Pengembangan Strategi Pelestarian Budaya di Sanggar Tari Bali Saraswati Yogyakarta dilakukan dalam empat langkah, yaitu menentukan lingkup penelitian yang terdiri dari lokasi penelitian, objek penelitian dan subjek penelitian. Langkah kedua, melakukan teknik pengumpulan data yang terdiri dari dua poin yaitu pengumpulan data primer dan pengumpulan data sekunder. Ketiga, menentukan variabel yang dilakukan melalui dua faktor, yaitu faktor internal (kekuatan dan kelemahan) dan faktor ekstenal (peluang dan ancaman). Langkah terakhir yaitu melakukan analisis data dengan metode kualitatif dengan analisis SWOT. Hasil penelitian pertama, berdasarkan matrik IE Sanggar Tari Bali Saraswati berada pada posisi IV yaitu Stability Strategy. Tidak menambahnya program dan kurikulum pembelajaran yang telah diterapkan sanggar namun, diperjelas lagi dari materi pembelajaran, kurikulum yang ada dan standar kelulusan siswa. Kedua, berdasarkan kuadran analisis SWOT Sanggar Tari Bali Saraswati berada pada kuadran IV, yaitu retrenchment strategy, melepaskan diri dari KPB Purantara atau menentukan sekretariat yang tepat untuk dijadikan secretariat sanggar adalah strategi yang tepat dilakukan. Ketiga, berdasarkan analisis matrik SWOT strategi umum yang diperoleh yaitu menyelenggarakan kegiatan lomba tari Bali setiap semester untuk anak-anak tingkat SD, SMP dan SMA se-Yogyakarta. Bekerja sama dengan panitia upacara keagamaan Hindu (pangempon Pura) yang ada di Yogyakarta. Memberikan kesempatan kepada siswa untuk ikut berpartisipasi dalam kegiatan pengabdian (ngayah) dan event yang mengatasnamakan Sanggar Tari Bali Saraswati. Perlu meningkatkan kesadaran dan rasa memiliki dari pengelola Sanggar Tari Bali Saraswati, anggota KPB (Keluarga Putra Bali) Purantara dan Asrama Bali. Kata kunci: pengembangan strategi, sanggar tari, analisis swot, formulasi strategi.
\end{abstract}

\footnotetext{
Abstract

5HM-DFK on Cultural Conservation Development Strategy at Bali Saraswati Dance Studio Yogyakarta aims to identify the strategy used at Bali Saraswati Dance Studio. In addition, to analyze the internal and external factors and formulate the development of strategies conducted by Bali Saraswati Dance Studio in Yogyakarta. The research method on Cultural Conservation Development Strategy at Bali Saraswati Dance Studio is done in four steps, those are determining the scope of research consisting of research location, research object and research subject. The second step, perform data collection techniques consisting of two points: primary data collection and secondary data collection. Third, determine the variables made through two factors, namely internal factors (strengths and weaknesses) and extensions (opportunities and threats). The last step is to perform data analysis with
} 
qualitative method with SWOT analysis. The results of the first study, based on the matrix IE Bali Saraswati Dance Studio is in the fourth position of Stability Strategy. Not adding to the program and learning curriculum that has been implemented by the studio but made clear from the learning materials, the existing curriculum and the students' graduation standard. Second, based on quadrant of SWOT analysis Bali Saraswati Dance Studio is in quadrant $I V$, that is retrenchment strategy, breaking away from KPB Purantara or determining the right secretariat to be used as studio secretariat is the right strategy to do. Third, based on SWOT matrix analysis, the general strategy obtained is to hold Balinese dance activity every semester for elementary, junior and senior high school students in Yogyakarta. In cooperation with the committee of Hindu religious ceremonies (Pangempon Pura) in Yogyakarta. Provide opportunities for students to participate in the activities of devotion (ngayah) and the event on behalf of Bali Saraswati Dance Studio. Need to increase awareness and sense of ownership of Bali Saraswati Dance Studio, member of KPB (Family of Putra Bali) Purantara and Bali Dormitory.

Keywords: strategy development, dance studio, swot analysis, strategy formulation

\section{Latar Belakang}

Akhir-akhir ini fenomena yang terjadi di Sanggar Tari Bali Saraswati yaitu mengenai perizinan sekretariat oleh Pemerintah Daerah Provinsi Bali. Menurut I Nyoman Cau Arsana selaku pengurus kesenian di KPB (Keluarga Putra Bali) Purantara, hal tersebut disebabkan bahwa Sanggar Tari Bali Saraswati belum memiliki tempat yang pasti sebagai sekretariat (wawancara, 1 Desember 2016). Saat ini kegiatan sanggar dilakukan di Asrama Putra Bali, Jalan Mawar, Baciro, Gondokusuman, Yogyakarta. Seharusnya tidak diperbolehkan untuk melakukan kegiatan di asrama karena merupakan tempat untuk tinggal, namun dari terbentuknya Sanggar Tari Bali Saraswati segala kegiatan dilakukan di Asrama Putra Bali. Menurut Ni Nyoman Seriati, selaku ketua Sanggar Tari Bali Saraswati, masalah yang ada di sanggar, yaitu mengenai perizinan penyelenggaraan oleh Pemerintah Daerah Bali dan struktur organisasi yang sekarang masih dengan ego masing-masing (wawancara, 11 Desember 2016). Walaupun izin dari Pemerintah Daerah Provinsi Bali belum dimiliki dan Dinas Kebudayan juga tidak dapat membantu dari segi biaya, hal itu tidak menyurutkan semangat pelaksanaan sanggar tersebut. Terbukti dari eksistensi dan keterlibatan Sanggar Tari Bali Saraswati di setiap kegiatan yang berkaitan dengan seni di Yogyakarta.

Data peserta latihan di Sanggar Tari Bali Saraswati terhitung dari lima periode terakhir menurut Ni Ketut Kanten (wawancara, 11 Desember 2016) selaku bendahara: 
Gambar 1:

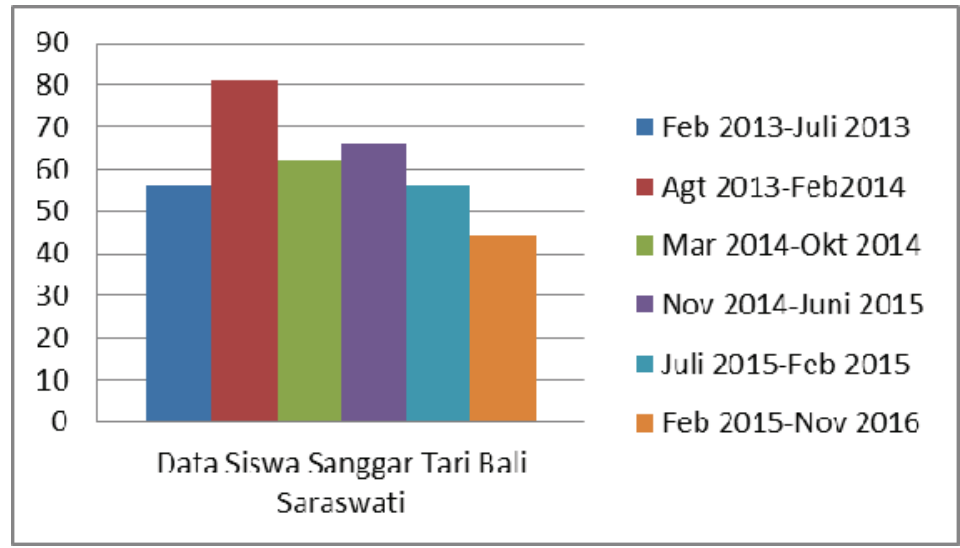

siswa

Diagram data

Melihat diagram tersebut, masalah-masalah yang terjadi di Sanggar Tari Bali Saraswati dapat memberi dampak bagi minat masyarakat untuk belajar menari. Terbukti bahwa tahun ini mengalami kemerosotan minat para peserta dan masyarakat sekitar. Hal tersebut juga terjadi akibat program dan kurikulum yang belum jelas karena setiap tahun ajaran baru pengurus sanggar harus melakukan rapat sebelum melakukan pelatihan karena perlu memikirkan dari segi sumber daya yang ada seperti kostum tari dan juga musik pengiringnya. Pengelola sanggar belum memiliki program jangka panjang atau program setiap tahunnya untuk pengembangan sanggar. Apakah mungkin ini disebabkan karena kegiatan sanggar tergolong kegiatan nonprofit, jadi masih menyepelekan hal-hal kecil yang sebenarnya dapat mempengaruhi pengembangan sanggar. Keluhan dari orang tua siswa juga menjadi hal yang sangat signifikan, hal ini disebabkan dari segi pengelola yang kurang teliti dalam hal pembayaran SPP siswa setiap bulannya. Melihat hal tersebut, penelitian terhadap sanggar ini penting dilakukan agar pengelolaan dan perkembangan Sanggar Tari Bali Saraswati ke depannya menjadi lebih baik.

\section{Landasan Teori}

\section{A. Strategi}

Strategi adalah kegiatan, mekanisme, atau sistem untuk mengantisipasi secara menyeluruh dan memprediksi pencapaian tujuan ke depan melalui pendekatan rasional (Pujiwiyana, 2012: 125). Dalam penelitian ini strategi disusun dengan memadukan antara Kekuatan (strength, S) dengan Peluang (opportunity, O) yang dikenal sebagai strategi SO; memadukan Kelemahan (weakness, W) dengan Peluang (opportunity, O) yang dikenal sebagai strategi W-O; dan memadukan Kekuatan (strength, S) dengan Ancaman (threath, T) yang dikenal sebagai strategi S-T.

\section{B. Pengembangan Strategi}

Proses pengembangan strategi dimulai dari pengembangan strategi korporat dengan focus mempertahankan hidup (survival). Penerapan strategi operasional ini berupa 
pengembangan struktur maupun infrastruktur. Pengembangan struktur meliputi: desain organisasi, evaluasi kapasitas, strategi mengenal fasilitas, sistem desain operasional (Rangkuti, 2016: 112). Maka dari itu, pengembangan strategi perlu diterapkan untuk memperoleh produk atau jasa yang sesuai dengan harapan konsumen.

\section{Pelestarian Budaya}

Merupakan upaya untuk merawat, mempertahankan, melindungi, dan mengembangkan warisan leluhur yang memiliki nilai guna untuk dilestarikan. Budaya tidak mungkin lestari jika dibekukan dalam ruang dan waktu. Pelestarian budaya tidak mungkin berupa pengawetan produk budaya di dalam museum untuk dilihat oleh generasi mendatang, pelestarian budaya harus berupa pelestarian cara hidup masyarakat sehingga generasi mendatang masih dapat menghidupi dan menjalani nilai-nilai yang ada dalam sebuah budaya (http//percikanrenunganblogspot.com/2011/08 diakses pada 20 Februari 2017 pukul 19.00 WIB). Dalam penelitian ini, peneliti menganalisis upaya dan memformulasikan strategi yang dilakukan Sanggar Tari Bali Saraswati dalam melestarikan budaya Bali di Yogyakarta. Dengan pelatihan tari Bali diharapkan mampu merealisasikan tujuan yang ingin dicapai sanggar tari tersebut.

\section{Sanggar Seni}

Menurut Kamus Bahasa Indonesia, sanggar merupakan tempat untuk mengadakan pertemuan atau tukar pikiran tentang suatu bidang ilmu atau bidang kegiatan tertentu. Menurut Hidayah, dkk (2012), sanggar atau bisa disebut sanggah mempunyai makna simbolis: Pertama, sebagai 'tempat pemujaan' yang terletak di pekarangan rumah, seperti terjadi di lingkungan pekarangan masyarakat Hindu di Bali pada umumnya. Kedua, bermakna sebagai tempat, wadah atau pusat untuk melaksanakan suatu kegiatan berkesenian (seni rupa, seni pertunjukan, dan seni multi media). Ketiga, mengandung arti tempat atau sarana yang digunakan oleh suatu komunitas atau sekumpulan orang untuk melakukan suatu kegiatan, yang di dalamnya termasuk sebagai tempat berlangsungnya proses pembelajaran.

Aktivitas pembinaan seni tradisional melalui sanggar tari dapat menjalankan fungsifungsi: religius, edukatif, sosial, hiburan, dan mata pencaharian. Kegiatan yang dikembangkan sebagai upaya untuk memberdayakan masyarakat secara sosial, ekonomi, di samping menjalankan fungsi pelestarian seni dan budaya tradisional. Tidak kalah penting juga bahwa aktivitas tersebut merupakan kegiatan pembelajaran masyarakat pada konteks pendidikan non formal.

\section{E. Formulasi Strategi}

Analisis SWOT sebagai alat formulasi strategi (Rangkuti, 2016: 19). Menurut David (2006), mengatakan bahwa formulasi strategi merupakan tahapan dari proses manajemen strategis yang terdiri dari tiga tahap, yakni: formulasi strategi, implementasi strategi, dan evaluasi strategi. Formulasi strategi termasuk mengembangkan visi dan misi, mengidentifikasi peluang dan ancaman eksternal perusahaan, menentukan kekuatan dan kelemahan internal, menetapkan tujuan jangka panjang, merumuskan alternatif strategi, dan memilih strategi tertentu yang akan dilaksanakan. Dalam penelitian ini, formulasi 
strategi memberikan temuan yang dapat memberikan peningkatan program pembelajaran dan kualitas sanggar serta mendapatkan strategi yang sebaiknya digunakan dalam pengembangan strategi pada Sanggar Tari Bali Saraswati di Yogyakarta.

\section{Metode Penelitian}

\section{A. Lingkup Penelitian}

1. Lokasi Penelitian

Penelitian ini dilakukan di Asrama Putra Bali Jalan Mawar, Baciro, Gondokusuman, Yogyakarta. Berada di sebelah utara Lapangan Mandala Krida.

2. Objek Penelitian

Objek penelitian ini adalah Sanggar Tari Bali Saraswati Yogyakarta beralamat di Asrama Putra Bali Jalan Mawar, Baciro, Gondokusuman, Yogyakarta. Berada di sebelah utara Lapangan Mandala Krida.

3. Subjek Penelitian

Subjek penelitian atau key persons dalam penelitian ini adalah sebagai berikut.
a) Pengelola
: I Wayan Senen (pendiri)
Ni Nyoman Seriati (ketua)
Ni Ketut Kanten (bendahara)
Ni Kadek Rai Dewi Astini (pelatih tari)
b) Orang tua siswa : Retno Dwi Intarti
Susan
$\begin{aligned} \text { c) Peserta/siswa : Putu Ayu Arindyasari } & \text { Salma Pradica Sandy }\end{aligned}$

B. Teknik Pengumpulan Data

1. Data Primer, yaitu data yang diperoleh secara langsung oleh peneliti (dari tangan pertama) dengan melakukan wawancara dan dokumentasi.

a. Wawancara, yakni kegiatan tanya jawab dengan key person bersifat semi terstruktur, dalam artian pertanyaan yang telah disusun dapat seketika berubah sesuai dengan alur pembicaraan.

b) Dokumentasi, pengumpulan dan pengolahan serta penyimpanan informasi data-data yang didapat untuk mendukung penelitian ini. Alat yang digunakan yaitu, perekam suara, kamera, dan video untuk memberikan data yang lebih akurat.

c) Kuesioner, instrumen penelitian yang digunakan dengan melalui daftar pertanyaan yang diisi oleh responden (key persons) dapat membantu dalam pengisian bobot dan rating.

2. Data Sekunder, yaitu data yang diperoleh peneliti dari sumber yang sudah ada, dari pihak pengelola, jurnal dari penelitian terdahulu, dan melalui website.

C. Variabel

Penelitian ini dilakukan melalui dua faktor, yakni faktor internal (kekuatan dan kelemahan) dan faktor eksternal (peluang dan ancaman). 
Analisis Faktor Internal:

Variabel Kekuatan:

1. Sanggar Tari Bali Saraswati merupakan salah satu pelatihan tari Bali di Yogyakarta.

2. Pelatih tari yang memiliki background tari Bali yang kuat.

3. Disponsori oleh Bimas (bimbingan masyarakat) dan Departemen Agama Hindu Yogyakarta.

4. Memiliki jaringan yang luas di Yogyakarta.

5. Dipercayai dalam mengisi kegiatan seni khususnya kesenian Bali di Yogyakarta. Variabel Kelemahan:

1. Pengelolaan yang tidak maksimal.

2. Program dan kurikulum pembelajaran yang tidak jelas.

3. Rendahnya keterlibatan anak jika ada event yang lebih besar.

4. Promosi yang kurang optimal.

5. Kurangnya kesadaran dari anggota KPB (Keluarga Putra Bali) Purantara dan Asrama Bali untuk mengembangkan sanggar.

Analisis Faktor Eksternal:

Variabel Peluang:

1. Kegiatan seni dan keagamaan Hindu di Yogyakarta.

2. Pelestarian nilai budaya Bali di Yogyakarta.

3. Penyewaan properti seni yang dimiliki sanggar untuk masyarakat sekitar.

4. Penyelenggaraan kegiatan lomba tari Bali yang diikuti oleh masyarakat Yogyakarta.

Variabel Ancaman:

1. Adanya sanggar tari Bali sejenis di Yogyakarta.

2. Menurunnya minat masyarakat Yogyakarta.

3. Pemda Bali melarang penyelenggaraan pelatihan di Sanggar Tari Bali Saraswati.

4. Sumber daya yang mulai berkurang.

D. Metode Analisis Data

Metode analisis data digunakan dalam penelitian ini adalah pendekatan kualitatif dengan menggunakan analisis SWOT untuk mendapatkan isian dari bobot dan rating. Analisis SWOT adalah identifikasi berbagai faktor secara sistematis untuk merumuskan strategi perusahaan (Rangkuti, 2016: 19) dan juga digunakan untuk mengukur variabelvariabel faktor internal dan faktor eksternal. Sebelum melakukan analisis SWOT (Strenghts, Opportunities, Weaknesses, Threats) terlebih dahulu menentukan key persons yang sangat berpengaruh terhadap Sanggar Tari Bali Saraswati. Tujuannya agar dapat membantu dalam pengisian bobot dan rating. Pengisian SWOT juga ditentukan dari saling negosiasi dengan key persons itu sendiri.

Formulasi strategi yang digunakan dalam penelitian ini adalah matriks IFAS dan EFAS. SWOT adalah sebuah alat pencocokkan yang penting yang membantu para manajer mengembangkan empat jenis strategi: Strategi SO (kekuatan-peluang), Strategi WO 
(kelemahan-peluang), Strategi ST (kekuatan-ancaman) dan Strategi WT (kelemahanancaman) (David, 2010: 327). Riset SWOT terdiri dari dua bagian, yakni:

1. Kondisi internal, tujuannya untuk mendapatkan faktor-faktor yang menjadi kekuatan dan kelemahan organisasi ini.

2. Kondisi eksternal, tujuannya untuk mendapatkan faktor-faktor yang menjadi peluang dan ancaman organisasi ini (Rangkuti, 2016:31).

Cara penghitungan bobot, rating dan score dalam matrik SWOT. Penghitungan bobot ditentukan berdasarkan tingkat kepentingan relatif suatu faktor terhadap keberhasilan perusahaan dalam suatu industri (Rangkuti, 2016:36).

Penentuan bobot pada setiap variabel digunakan skala 1, 2, 3. Penilaian untuk setiap skala dapat dijelaskan sebagai berikut:

$1=$ jika indikator horizontal kurang penting daripada indikator vertikal

$2=$ jika indikator horizontal sama penting dengan indikator vertikal

$3=$ jika indikator horizontal lebih penting daripada indikator vertical

Bobot setiap variabel diperoleh dengan membagi jumlah nilai setiap variabel terhadap jumlah nilai keseluruhan variabel dengan menggunakan rumus:

$$
\begin{aligned}
\mathrm{ai}_{\mathrm{i}}=\frac{\mathrm{X}_{\mathrm{i}}}{\sum \mathrm{X}_{\mathrm{i}}} \quad \text { Keterangan }: \quad \mathrm{ai}_{\mathrm{i}} & =\text { Bobot variabel ke- } \mathrm{i} \\
\mathrm{X}_{\mathrm{i}} & =\text { Nilai variabel ke- } \mathrm{i} \\
\mathrm{i} & =\text { ke } 1,2,3, \ldots
\end{aligned}
$$

Tabel 1: Penilaian Bobot Faktor Internal atau Eksternal Perusahaan

\begin{tabular}{|l|l|l|l|l|l|}
\hline $\begin{array}{l}\text { Faktor Internal/ } \\
\text { Faktor Eksternal }\end{array}$ & & & & & Total \\
\hline A & & & & & \\
\hline B & 1 & & 2 & & \\
\hline C & & 2 & & 1 & \\
\hline D & & & 3 & & \\
\hline Total & & & & & \\
\hline
\end{tabular}

Sumber: David (2010)

Rating adalah analisis kita terhadap kemungkinan yang akan terjadi dalam jangka pendek (misalnya satu tahun ke depan) (Rangkuti, 2016: 36). Penilaian rating menurut Rangkuti tahun 2016, untuk variabel internal dan eksternal diberikan dalam skala dengan pembagian sebagai berikut:

Variabel Eksternal

Aspek Peluang:

rating $4=$ respon sangat superior, rating 3 = respon di atas rata-rata, rating 2 = respon rata-rata, dan rating $1=$ respon di bawah rata-rata
Aspek Ancaman:

rating $4=$ respon di bawah rata-rata, rating $3=$ respon rata-rata, rating $2=$ respon di atas rata-rata, dan rating $1=$ respon sangat superior 
Variabel Internal

Aspek Kekuatan:

Aspek Kelemahan:

rating $4=$ sangat kuat,

rating $4=$ sangat lemah,

rating $3=$ kuat,

rating 3 = lemah,

rating 2 = lemah, dan

rating 2 = kuat, dan

rating 1 = sangat lemah

rating $1=$ sangat kuat

Nilai score diperoleh berdasarkan hasil nilai bobot dikali nilai rating. Total nilai score untuk faktor internal menunjukkan bahwa semakin nilainya mendekati 1, semakin banyak kelemahan internal dibandingkan kekuatannya. Sedangkan semakin nilainya mendekati 4, semakin banyak kekuatan dibandingkan kelemahannya. Begitu juga dengan total nilai score untuk faktor eksternal. Semakin total nilai score mendekati 1, semakin banyak ancamannya dibandingkan dengan peluang. Sedangkan apabila total nilai score mendekati 4, artinya semakin banyak peluang dibandingkan ancaman (Rangkuti, 2016:36-37). Menurut Fred R. David (2010:327), bahwa untuk mencocokkan faktor-faktor eksternal dan internal merupakan bagian tersulit dalam mengembangkan matriks SWOT dan membutuhkan penilaian yang baik. Berikut penjelasan mengenai empat kemungkinan alternatif strategi, yaitu:

1. Strategi SO, memanfaatkan kekuatan internal perusahaan untuk menarik keuntungan dari peluang eksternal.

2. Strategi WO, bertujuan untuk memperbaiki kelemahan internal dengan cara mengambil keuntungan dari peluang eksternal.

3. Strategi ST, menggunakan kekuatan sebuah perusahaan untuk menghindari atau mengurangi dampak ancaman eksternal.

4. Strategi WT, merupakan taktik defensif yang diarahkan untuk mengurangi kelemahan internal serta menghindari ancaman eksternal.

\section{Analisis dan Pembahasan}

Dalam penelitian ini penulis menggunakan metode kualitatif dengan analisis SWOT. Kemudian menganalisis tiga tahap formulasi yang terdiri dari, tahap pemasukan yaitu analisis lingkungan internal dan eksternal (IFE dan EFE), tahap pencocokkan yaitu analisis matriks IE, kuadran analisis SWOT, dan matriks SWOT Sanggar Tari Bali Saraswati Yogyakarta serta tahap keputusan yang dihasilkan berdasarkan ketiga poin pada tahap pencocokkan.

\section{Tahap Pemasukan}

Melalui alat bantu kuesioner kepada delapan key persons diperoleh data yang disajikan melalui beberapa tabel sebagai berikut: 
Tabel 2: Hasil Analisis Matriks IFE

\begin{tabular}{|c|l|c|c|c|}
\hline No & \multicolumn{1}{|c|}{ IFE Matriks (Internal) Kekuatan dan Kelemahan } & Bobot & Peringkat & Skor \\
\hline A & $\begin{array}{l}\text { Sanggar Tari Bali Saraswati merupakan salah satu pelatihan } \\
\text { tari Bali di Yogyakarta. }\end{array}$ & 0,08 & 3,63 & 0,29 \\
\hline B & Pelatih tari yang memiliki background tari Bali yang kuat. & 0,07 & 3,75 & 0,26 \\
\hline C & $\begin{array}{l}\text { Disponsori oleh Bimas (bimbingan masyarakat) dan } \\
\text { Departemen Agama Hindu Yogyakarta. }\end{array}$ & 0,11 & 2,75 & 0,30 \\
\hline D & Memiliki jaringan yang luas di Yogyakarta. & 0,09 & 3,25 & 0,29 \\
\hline E & $\begin{array}{l}\text { Dipercayai dalam mengisi kegiatan seni khususnya kesenian } \\
\text { Bali di Yogyakarta. }\end{array}$ & 0,07 & 3,75 & 0,26 \\
\hline F & Pengelolaan yang tidak optimal. & 0,11 & 2,63 & 0,29 \\
\hline G & Program dan kurikulum pembelajaran yang tidak jelas. & 0,13 & 3,25 & 0,42 \\
\hline H & Rendahnya keterlibatan anak jika ada event yang lebih & 0,13 & 3,13 & 0,41 \\
\hline I & Promosi yang kurang optimal. & 0,12 & 2,88 & 0,35 \\
\hline J & $\begin{array}{l}\text { Kurangnya kesadaran dari anggota KPB (Keluarga Putra } \\
\text { Bali) Purantara dan Asrama Bali untuk mengembangkan } \\
\text { sanggar. }\end{array}$ & 0,12 & 3,00 & \multirow{2}{*}{0,36} \\
\hline \multicolumn{2}{|l|}{ Total Skor IFE Matriks } & 3,23 & \\
\hline
\end{tabular}

Pada tabel 2 hasil analisis matriks IFE terhadap Pengembangan Strategi Pelestarian Budaya di Sanggar Tari Bali Saraswati Yogyakarta skor tertinggi adalah (G) Program dan kurikulum pembelajaran yang tidak jelas yaitu sebesar 0,42 , sedangkan yang terendah ada dua, yaitu (B) Pelatih tari yang memiliki background tari Bali yang kuat dan (E) Dipercayai dalam mengisi kegiatan seni khususnya kesenian Bali di Yogyakarta dengan skor 0,26 . 
Tabel 3: Hasil Analisis Matriks EFE

\begin{tabular}{|c|l|c|c|c|}
\hline No & EFE Matrik (Eksternal) Peluang dan Ancaman & Bobot & Peringkat & Skor \\
\hline A & $\begin{array}{l}\text { Banyaknya kegiatan seni dan keagamaan Hindu di } \\
\text { Yogyakarta. }\end{array}$ & 0,09 & 3,38 & 0,30 \\
\hline B & Pelestarian nilai budaya Bali di Yogyakarta. & 0,08 & 3,63 & 0,29 \\
\hline C & $\begin{array}{l}\text { Dapat menyewakan properti seni yang dimiliki sanggar } \\
\text { untuk masyarakat sekitar. }\end{array}$ & 0,11 & 2,88 & 0,32 \\
\hline D & $\begin{array}{l}\text { Membuat event atau kegiatan lomba tari Bali yang diikuti } \\
\text { oleh masyarakat Yogyakarta. }\end{array}$ & 0,14 & 2,13 & 0,30 \\
\hline E & Memiliki pesaing yang sejenis. & 0,12 & 2,38 & 0,29 \\
\hline F & Minat masyarakat mulai menurun. & 0,15 & 3,13 & 0,47 \\
\hline G & $\begin{array}{l}\text { Pemerintah Daerah Bali melarang penyelenggaraan } \\
\text { pelatihan di Sanggar Tari Bali Saraswati. }\end{array}$ & 0,17 & 3,75 & 0,64 \\
\hline H & Sumber daya yang mulai berkurang. & 0,14 & 2,63 & 0,37 \\
\hline Total Skor EFE Matriks & & 2,97 & \\
\hline
\end{tabular}

Pada tabel 3 hasil analisis matriks EFE terhadap Pengembangan Strategi Pelestarian Budaya di Sanggar Tari Bali Saraswati Yogyakarta skor tertinggi adalah (G) Pemerintah Daerah Bali melarang penyelenggaraan pelatihan di Sanggar Tari Bali Saraswati yaitu sebesar 0,64, sedangkan yang terendah ada dua, yaitu (B) Pelestarian nilai budaya Bali di Yogyakarta dan (E) Memiliki pesaing yang sejenis dengan skor 0,29.

\section{Tahap Pencocokkan}

Pada tahap pencocokan, hasil perhitungan di atas diperoleh hasil IFE sebesar 3,23 dan EFE sebesar 2,97. Angka tersebut selanjutnya dapat menggambarkan posisi Pengembangan Strategi Pelestarian Budaya di Sanggar Tari Bali Saraswati Yogyakarta melalui matriks IE sebagai berikut.

Matriks IE Sanggar Tari Bali

Saraswati

The IFE total

weighted score

$\begin{array}{llllll}4.0 & \text { Strong } & 3.0 & \text { Average } & \text { Weak } & \\ & & & & & \end{array}$

\begin{tabular}{|c|c|c|c|c|c|}
\hline I & II & III & 3.0 & High & $\begin{array}{l}\text { The EFE } \\
\text { total }\end{array}$ \\
\hline IV & $\mathrm{V}$ & VI & 2.0 & Medium & $\begin{array}{l}\text { weighted } \\
\text { score }\end{array}$ \\
\hline VII & VIII & IX & 1.0 & Low & \\
\hline
\end{tabular}

$\mathrm{IFE}=3,23$

$\mathrm{EFE}=2,97$ 
Berdasarkan hasil dari matriks IE Sanggar Tari Bali Saraswati berada pada posisi IV yaitu Stability strategy. Stability strategy adalah strategi yang diterapkan tanpa mengubah arah strategi yang telah diterapkan (Rangkuti, 2016: 95). Menurut Glueck pada modul pembelajaran Strategi Generik, Variasi Strategi, Porter's Five Generic Strategies dinyatakan bahwa pada prinsipnya strategi ini menekankan pada tidak bertambahnya produk, pasar, dan fungsi-fungsi Sanggar Tari Bali Saraswati.

Tabel 4: Bobot Skor Kekuatan

\begin{tabular}{|c|l|c|c|c|}
\hline No & \multicolumn{1}{|c|}{ Kekuatan } & Bobot & Peringkat & Skor \\
\hline A & $\begin{array}{l}\text { Sanggar Tari Bali Saraswati merupakan salah satu } \\
\text { pelatihan tari Bali di Yogyakarta. }\end{array}$ & 0,08 & 3,63 & 0,29 \\
\hline B & $\begin{array}{l}\text { Pelatih tari yang memiliki background tari Bali } \\
\text { yang kuat. }\end{array}$ & 0,07 & 3,75 & 0,26 \\
\hline C & $\begin{array}{l}\text { Disponsori oleh Bimas (bimbingan masyarakat) } \\
\text { dan Departemen Agama Hindu Yogyakarta. }\end{array}$ & 0,11 & 2,75 & 0,30 \\
\hline D & Memiliki jaringan yang luas di Yogyakarta. & 0,09 & 3,25 & 0,29 \\
\hline E & $\begin{array}{l}\text { Dipercayai dalam mengisi kegiatan seni khususnya } \\
\text { kesenian Bali di Yogyakarta. }\end{array}$ & 0,07 & 3,75 & 0,26 \\
\hline \multicolumn{2}{|l}{} & & 1,40 \\
\hline
\end{tabular}

Tabel 5: Bobot Skor Kelemahan

\begin{tabular}{|c|l|c|c|c|}
\hline No & \multicolumn{1}{|c|}{ Kelemahan } & Bobot & Peringkat & Skor \\
\hline F & Pengelolaan yang tidak optimal. & 0,11 & 2,63 & 0,29 \\
\hline G & $\begin{array}{l}\text { Program dan kurikulum pembelajaran yang tidak } \\
\text { jelas. }\end{array}$ & 0,13 & 3,25 & 0,42 \\
\hline H & $\begin{array}{l}\text { Rendahnya keterlibatan anak jika ada event } \\
\text { yang lebih besar. }\end{array}$ & 0,13 & 3,13 & 0,41 \\
\hline I & Promosi yang kurang optimal. & 0,12 & 2,88 & 0,35 \\
\hline J & $\begin{array}{l}\text { Kurangnya kesadaran dari anggota KPB } \\
\text { (Keluarga Putra Bali) Purantara dan Asrama } \\
\text { Bali untuk mengembangkan sanggar. }\end{array}$ & 0,12 & 3,00 & 0,36 \\
\hline & \multicolumn{1}{|l}{} & & 1,83 \\
\hline
\end{tabular}

$$
\begin{aligned}
\text { Bobot Skor Faktor Internal } & =\text { Kekuatan }- \text { Kelemahan } \\
& =1,40-1,83 \\
& =-0,43
\end{aligned}
$$

Tabel 6: Bobot Skor Peluang

\begin{tabular}{|c|l|c|c|c|}
\hline No & \multicolumn{1}{|c|}{ Peluang } & Bobot & Peringkat & Skor \\
\hline A & $\begin{array}{l}\text { Banyaknya kegiatan seni dan keagamaan Hindu } \\
\text { di Yogyakarta. }\end{array}$ & 0,09 & 3,38 & 0,30 \\
\hline B & Pelestarian nilai budaya Bali di Yogyakarta. & 0,08 & 3,63 & 0,29 \\
\hline C & $\begin{array}{l}\text { Dapat menyewakan properti seni yang dimiliki } \\
\text { sanggar untuk masyarakat sekitar. }\end{array}$ & 0,11 & 2,88 & 0,32 \\
\hline D & $\begin{array}{l}\text { Membuat } \text { event atau kegiatan lomba tari Bali } \\
\text { yang diikuti oleh masyarakat Yogyakarta. }\end{array}$ & 0,14 & 2,13 & 0,30 \\
\hline \multicolumn{2}{|l|}{} & 1,21 \\
\hline
\end{tabular}


Tabel 7: Bobot Skor Ancaman

\begin{tabular}{|l|l|l|l|l|}
\hline No & \multicolumn{1}{|c|}{ Ancaman } & Bobot & Peringkat & \multicolumn{1}{|c|}{ Skor } \\
\hline E & Memiliki pesaing yang sejenis. & 0,12 & 2,38 & 0,29 \\
\hline F & Minat masyarakat mulai menurun. & 0,15 & 3,13 & 0,47 \\
\hline G & $\begin{array}{l}\text { Pemerintah Daerah Bali melarang penyelenggaraan } \\
\text { pelatihan di Sanggar Tari Bali Saraswati. }\end{array}$ & 0,17 & 3,75 & 0,64 \\
\hline H & Sumber daya yang mulai berkurang. & 0,14 & 2,63 & 0,37 \\
\hline \multicolumn{2}{|l}{} & 1,77 \\
\hline
\end{tabular}

$$
\begin{aligned}
\text { Bobot Skor Faktor Eksternal } & =\text { Peluang }- \text { Ancaman } \\
& =1,21-1,77 \\
& =-0,56
\end{aligned}
$$

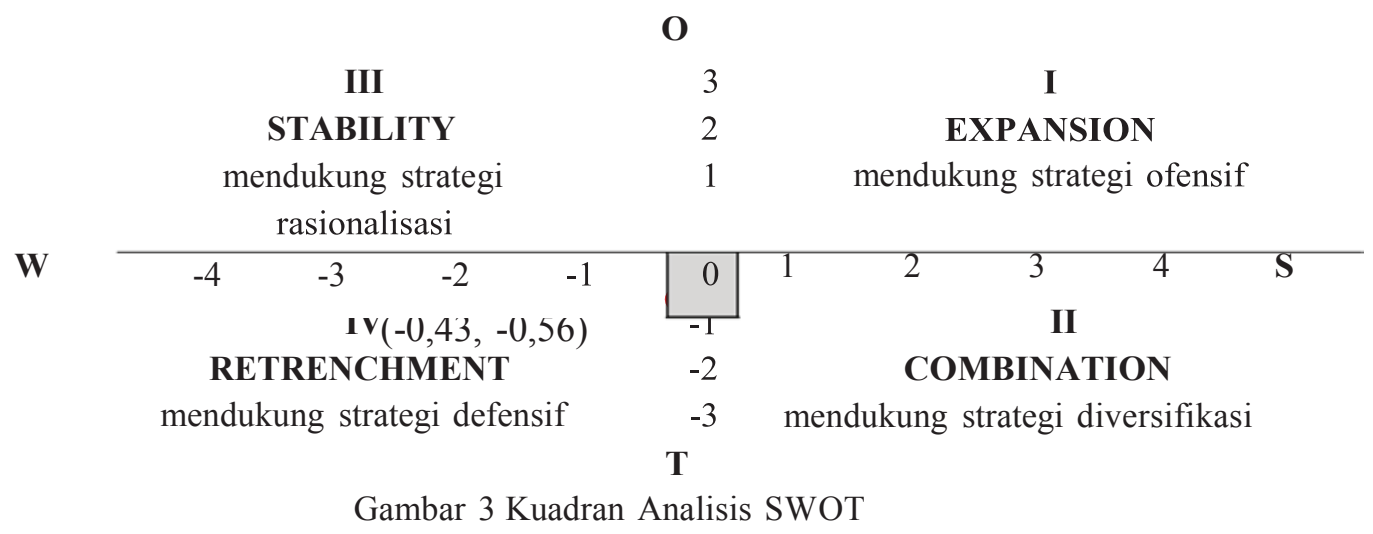

Berdasarkan hasil dari Kuadran Analisis SWOT Sanggar Tari Bali Saraswati berada pada posisi kuadran IV, yaitu retrenchment strategy adalah usaha memperkecil atau mengurangi usaha yang dilakukan Sanggar Tari Bali Saraswati (Rangkuti, 2016: 96). Menurut Glueck pada modul pembelajaran Strategi Generik, Variasi Strategi, Porter's Five Generic Strategies dinyatakan bahwa retrenchment strategy adalah strategi untuk melakukan pengurangan atas pasar maupun fungsi-fungsi dalam perusahaan yang memiliki aliran keuangan (cash flow) negatif. Biasanya strategi ini diterapkan pada perusahaan yang berada pada tahap menurun.

\section{Tahap Keputusan}

A. Berdasarkan Matriks IE

Berdasarkan Matriks IE, Sanggar Tari Bali Saraswati berada pada posisi IV yaitu stability strategy pada Sanggar Tari Bali Saraswati menunjukkan bahwa skor factor internal lebih besar dari faktor eksternal. Maka Sanggar Tari Bali Saraswati mendukung faktor internal. Sesuai dengan pengertian stability strategy bahwa strategi ini menekankan pada tidak bertambahnya produk, segmentasi pasar dan fungsi Sanggar Tari Bali Saraswati. Tidak 
bertambahnya produk yang dimaksud adalah tidak menambahnya program dan kurikulum pembelajaran yang telah diterapkan sanggar namun diperjelas lagi dari materi pembelajaran, kurikulum yang ada dan standar kelulusan siswa. Karena melihat dari skor IFE matriks bahwa program dan kurikulum pembelajaran yang tidak jelas berada pada skor tertinggi yaitu 0,42 pada variabel kelemahan bagian G. Segmentasi pasar Sanggar Tari Bali Saraswati hanya dapat berkembang di Yogyakarta, hal ini disebabkan karena skor pada faktor kelemahan (I) promosi kurang optimal lebih besar dibandingkan dengan faktor kekuatan (D) Sanggar Tari Bali Saraswati memiliki jaringan yang luas di Yogyakarta dan pernyataan ini didukung pada variabel peluang bahwa (A) Banyaknya kegiatan seni dan keagamaan Hindu di Yogyakarta. Tidak bertambahnya fungsi Sanggar Tari Bali Saraswati dimaksud yaitu tetap berkomitmen dengan visi sanggar melalui kesenian, pengabdian (ngayah) menjadi salah satu upaya pelestarian dan pengenalan budaya Bali di Yogyakarta. Hal ini dibuktikan berdasarkan skor terendah pada analisis matriks EFE adalah pelestarian budaya Bali di Yogyakarta pada variabel peluang B yaitu dengan skor 0,29.

\section{B. Berdasarkan Kuadran Analisis SWOT}

Berdasarkan kuadran analisis SWOT, Sanggar Tari Bali Saraswati berada pada kuadran IV, yaitu retrenchment strategy. Strategi ini terkadang dikenal sebagai strategi turn around atau reorganizational. Tujuan dari strategi ini adalah untuk memperkokoh keunggulan yang membedakan (distinctive competences) yang dimiliki Sanggar Tari Bali Saraswati. Sanggar Tari Bali Saraswati berada pada posisi retrenchment atau penciutan karena skor pada faktor kelemahan dan ancaman lebih besar dibanding faktor kekuatan dan peluang. Skor tertinggi pada bobot skor kekuatan yaitu (C) Disponsori oleh Bimas (bimbingan masyarakat) dan Departemen Agama Hindu Yogyakarta dengan skor 0,30 dan pada bobot skor kelemahan yaitu $(G)$ program dan kurikulum pembelajaran yang tidak jelas dengan skor 0,42 . Skor total pada kekuatan yaitu 0,40 sedangkan skor total pada kelemahan 1,83, berdasarkan dari hasil perhitungan tersebut maka perlu mempertimbangkan beberapa indikator-indikator yang berada pada variabel kelemahan. Indikator pada kelemahan tersebut mengindikasikan untuk melakukan suatu strategi penciutan atau retrenchment. Langkah-langkahnya adalah melakukan pengurangan atas pasar maupun fungsi-fungsi dalam sanggar. Pada variabel kelemahan menunjukkan bahwa $(\mathrm{G})$ program dan kurikulum pembelajaran yang tidak jelas berada pada skor tertinggi 0,42 berdasarkan hasil skor ini bukan dimaksud mengurangi program dan kurikulum namun memperjelas program dan kurikulum dari sanggar tersebut.

Memperjelas dalam pengertiannya yaitu materi yang diberikan kepada siswa lebih jelas sesuai dengan tingkatan kemampuannya, menyesuaikan dengan strandar kelulusan siswa, kualitas pelatih dan metode pembelajaran harus diperjelas lagi. Begitu juga pada indikator variabel ancaman skor yang lebih besar yaitu Pemerintah Daerah Bali melarang penyelenggaraan pelatihan di Sanggar Tari Bali Saraswati dengan skor 0,64. Berdasarkan faktor ancaman tersebut maka langkah strategi yang tepat dilakukan adalah memisahkan diri dari payung KPB Purantara atau menentukan sekretariat yang tepat (strategis) untuk dijadikan sekretariat sanggar.

Saat ini operasi sanggar berjalan dengan sumber daya (terutama dana) yang terbatas dan berada pada kondisi penuh tekanan dari berbagai pihak seperti Pemerintah Daerah Bali mempermasalahkan mengenai perizinan, kesadaran anggota sanggar (pengelola sanggar, 
KPB Purantara dan Asrama Bali), minat siswa dan orang tua siswa mulai menurun. Strategi penciutan dapat berbentuk penjualan aset untuk memperoleh dana tunai, pemangkasan lini produk (product line), menutup bisnis yang kurang menguntungkan atau yang tidak termasuk core competence sanggar, otomasi proses, pengurangan jumlah pengajar, dan penerapan sistem kontrol pengeluaran biaya. (https://mustamu.wordpress.com/2009/01/12/tipe-tipe-strategi/ diakses pada tanggal 25 Mei 2017).

Pernyataan tersebut dibenarkan oleh Ni Ketut Kanten selaku bendahara bahwa untuk mengurangi dana yang dikeluarkan sebagai honorarium pengajar maka dilakukanlah pengurangan dalam jumlah pengajar. Dahulunya jumlah pengajar sejumlah lima orang namun saat ini pengajar di Sanggar Tari Bali Saraswati berjumlah tiga orang, yaitu Ni Kadek Rai Dewi Astini, Ni Nyoman Seriati dan Kadek Sumiasih.

Dibalik popularitas Sanggar Tari Bali Saraswati dari tahun 1950-an hingga 2017 di Yogyakarta, terdapat masalah yang sangat signifikan yang dapat membuat sanggar ini tidak memiliki kepastian hukum (legalitas). Menurut Ni Nyoman Seriati selaku ketua Sanggar Tari Bali Saraswati mengatakan bahwa, "Sanggar ini sebenarnya belum memiliki legalitas dan belum berbadan hukum, maka dari itu hingga saat ini Pemda Bali menanyakan masalah perinzinan dari adanya sanggar ini. Akibat belum adanya izin tersebut maka saat ini tidak diperbolehkan memasang plang nama sanggar dan juga melakukan kegiatan pelatihan" (wawancara, 7 Mei 2017). Hal ini disebabkan karena sanggar berada di bawah payung KPB (Keluarga Putra Bali) Purantara dan KPB belum berbadan hukum. Kemudian timbul wacana apakah Sanggar Tari Bali Saraswati akan tetap bertahan dengan masalah yang ada atau akan berdiri sendiri (keluar dari KPB Purantara) agar mempermudah dalam hal perizinan dan legalitas.

\section{Berdasarkan Matriks SWOT}

Posisi Sanggar Tari Bali Saraswati Yogyakarta dalam pengembangan strategi pelestarian budaya melalui Matriks IE menunjukkan Stability strategy karena berada pada posisi IV. Stability strategy adalah strategi yang diterapkan tanpa mengubah arah strategi yang telah diterapkan (Rangkuti, 2016: 95). Strategi ini menekankan pada tidak bertambahnya produk, pasar dan fungsi-fungsi perusahaan karena berusaha untuk meningkatkan efisiensi di segala bidang dalam rangka meningkatkan kinerja dan keuntungan. Strategi ini relatif rendah resiko dan biasanya dilakukan untuk produk yang tengah berada pada posisi matang/dewasa (maturity). Sehingga strategi umum yang diperoleh adalah:

1. Bekerja sama dengan panitia upacara keagamaan Hindu (pangempon Pura) yang ada di Yogyakarta selain untuk menghaturkan sujud bakti (ngayah) ke hadapan Tuhan, dapat menjadi salah satu cara mempromosikan keberadaan sanggar dan menambah minat siswa. Serta dengan hal itu pelestarian budaya Bali di Yogyakarta dapat berjalan dengan baik.

2. Menyelenggarakan kegiatan lomba tari Bali setiap semester untuk anak-anak tingkat SD, SMP dan SMA se-Yogyakarta yang dapat membantu dalam hal promosi sanggar dan juga Sanggar Tari Bali Saraswati menjadi lebih eksis di Yogyakarta.

3. Memberikan kesempatan kepada siswa untuk ikut berpartisipasi dalam kegiatan pengabdian (ngayah) dan event yang mengatasnamakan Sanggar Tari Bali Saraswati. 
4. Perlu meningkatkan kesadaran dan rasa memiliki dari pengelola Sanggar Tari Bali Saraswati, anggota KPB (Keluarga Putra Bali) Purantara dan Asrama Bali untuk mengembangkan Sanggar Tari Bali Saraswati di Yogyakarta.

5. Perlu adanya regenerasi pengurus pengelola untuk mendapatkan inovasi baru dengan diawasi pengurus yang terdahulu dalam mengembangkan Sanggar Tari Bali Saraswati.

\section{Kesimpulan}

Berdasarkan permasalahan yang diajukan dalam penelitian ini maka hasil yang diperoleh adalah sebagai berikut.

1. Berdasarkan Matriks IE Sanggar Tari Bali Saraswati berada pada posisi IV yaitu Stability Strategy. Melihat hasil dari matriks IE dinyatakan bahwa sanggar dalam keadaan stabil bahwa strategi ini menekankan pada tidak bertambahnya produk, segmentasi pasar dan fungsi Sanggar Tari Bali Saraswati.

2. Berdasarkan kuadran analisis SWOT Sanggar Tari Bali Saraswati berada pada kuadran IV, yaitu retrenchment strategy. Melihat posisi Sanggar Tari Bali berada dalam retrenchment strategy maka, langkah strategi yang tepat dilakukan adalah memisahkan diri dari payung KPB Purantara atau menentukan sekretariat yang tepat (strategis) untuk dijadikan sekretariat sanggar.

3. Berdasarkan analisis mengenai matriks SWOT terdapat strategi umum yang diperoleh, yaitu menyelenggarakan kegiatan lomba tari Bali setiap semester untuk anak-anak tingkat SD, SMP, dan SMA se-Yogyakarta. Bekerja sama dengan panitia upacara keagamaan Hindu (pangempon Pura) yang ada di Yogyakarta. Perlu meningkatkan kesadaran dan rasa memiliki dari pengelola Sanggar Tari Bali Saraswati, anggota KPB (Keluarga Putra Bali) Purantara dan Asrama Bali untuk mengembangkan Sanggar Tari Bali Saraswati di Yogyakarta.

\section{Kepustakaan}

David, Fred R. 2010. Manajemen Strategis. Jakarta: Salemba Empat.

Pujiwiyana. 2012. Manajemen Program Pelatihan Seni Tradisional pada Sanggar Seni Sekar Wijaya Kusuma sebagai Upaya Pemberdayaan Masyarakat dalam Jurnal Imaji Vol. 10 No. 2: Yogyakarta: Universitas Negeri Yogyakarta.

Rangkuti, Freddry. 2016. Analisis SWOT: Teknis Membedah Kasus Bisnis Cara Perhitungan Bobot, Ratting dan OCAI. Jakarta: PT Gramedia Pustaka Utama.

\section{Sumber wawancara}

I Nyoman Cau Arsana. Bagian Kesenian di KPB dan Dosen Etnomusikologi. Wawancara langsung di Basemen Tari, 1 Desember 2016, pukul 22.00 WIB (30 menit).

Ni Nyoman Seriati. Ketua Sanggar Tari Bali Saraswati dan Dosen Tari UNY. Wawancara langsung di Sanggar Tari Bali Saraswati, 11 Desember 2016, pukul 09.00 WIB (60 menit) dan 7 Mei 2017 di Sanggar Tari Bali Saraswati pukul 08.00 WIB (26 menit). 
Ni Ketut Kanten. Bendahara Sanggar Tari Bali Saraswati. Wawancara langsung di Sanggar

Tari Bali Saraswati, tanggal 7 Mei 2017 di Sanggar Tari Bali Saraswati pukul 10.00 WIB (25 menit).

\section{Sumber internet}

http:/hariannetral.com/2014/12/pengertian-strategi-menurut-beberapaahli.html diakses pada tanggal 30 November 2016, pukul 18.00 WIB.

https://mustamu.wordpress.com/2009/01/12/tipe-tipe-strategi/

diakses pada tanggal 25 Mei 2017, pukul 23.00 WIB.

Lampiran Foto

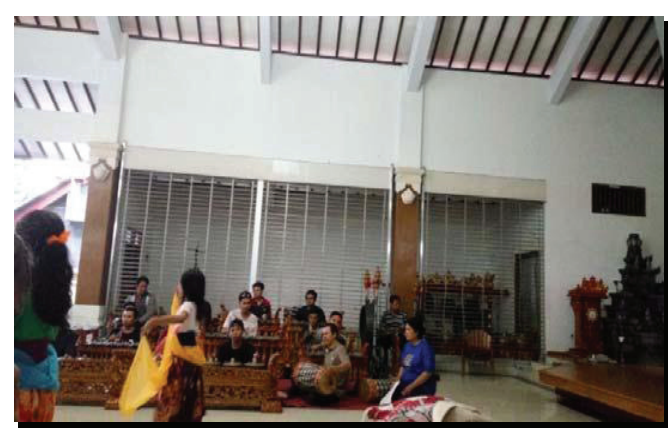

Gambar 1. KPB Purantara

(Foto: Merina, 2016)

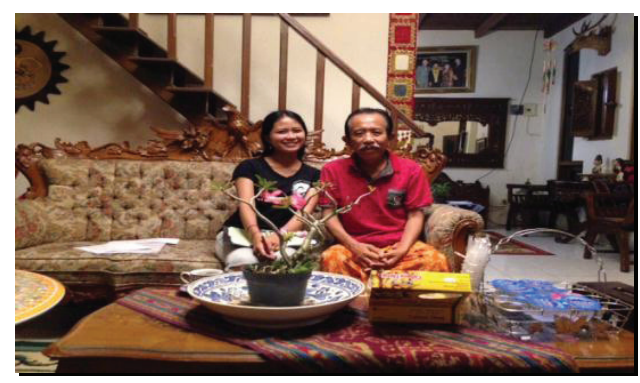

Gambar 3. Wawancara dengan I Wayan Senen

(Foto: Merina, 2017)

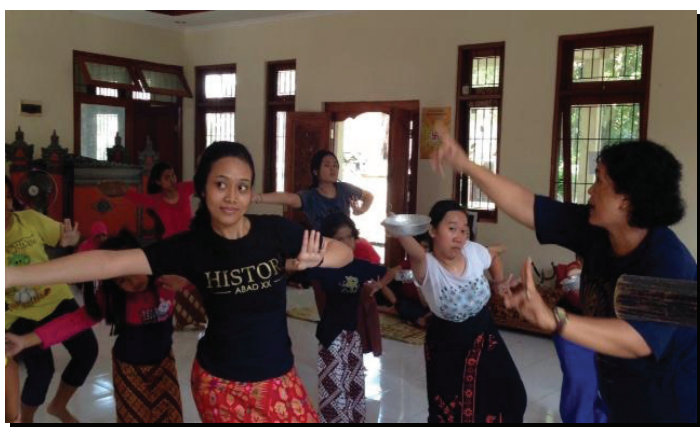

Gambar 5. Siswa belajar tari Condong (Foto: Merina, 2017)

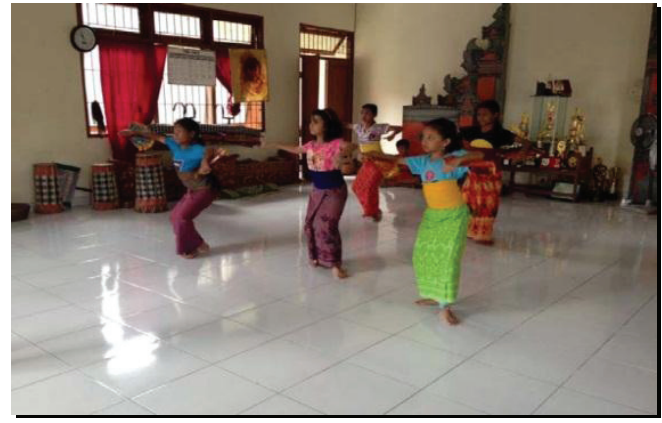

Gambar 2. Siswa belajar tari Kupu-Kupu Tarum

(Foto: Merina, 2016)

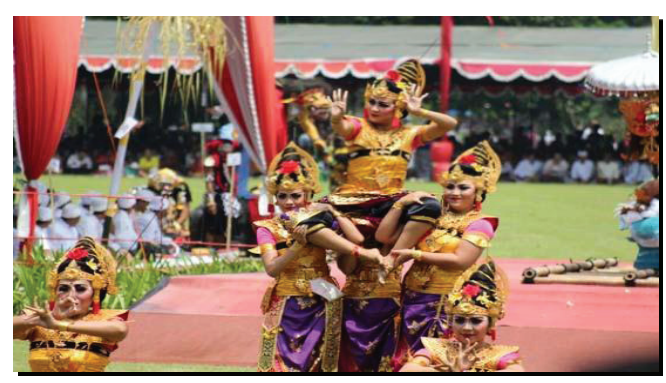

Gambar 4. Sendratari Pamutaring Gunung Mandara Giri pada Acara Tawur Kesanga

(Foto: Merina, 2017)

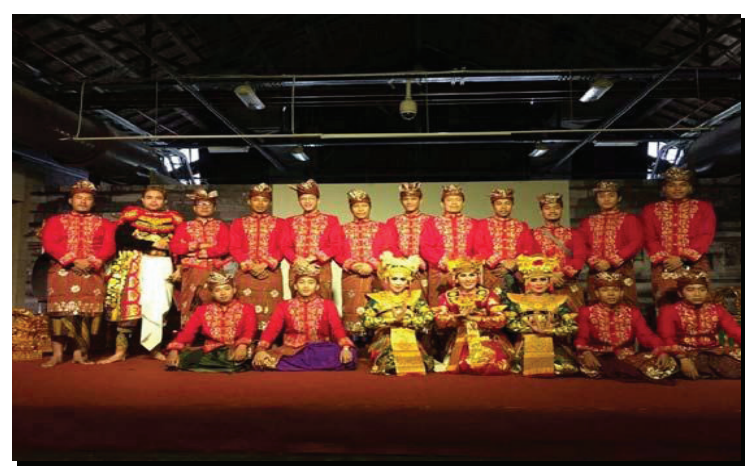

Gambar 6 Festival Budaya di Taiwan (Foto: Merina, 2017) 